$\frac{12}{3-21}-94850$

UCRLID-116389

\title{
Destruction of XM-46 (aka LGP-1846) Using the Molten Salt Destruction Process
}

\author{
Ravindra S. Upadhye and Bruce E. Watkins
}

March 1994

This is an informal repost intended primarily for thternal or Hodted external distribution. The opinions and enchusions ctated are those of the auther and any or may not be thowe of the Labendery.

Work performed under the arrices of the U.S. Departenent of Enary by the Luwrence Livermore National Liberatory under Contrect W-7cos-Eng 48. 


\section{DISCLAIMER}

This document was prepared as an account of work sponsored by an agency of the United States Government. Neither the United States Government nor the University of California nor any of their employees, makes any warranty, exf ress or implied, or assumes any legal liability or responsibility for the accuracy, completeness, or usefulness of any information, apparatus, product, or process disclosed, or represents that its use would not infringe privately owned rights. Reference herein to any specific commercial products, process, or service by trade name, trademark, manufacturer, or otherwise, does not necessarily constitute or imply its endorsement, recommendation, or favoring by the United States Government or the University of California. The views and opinions of authors expressed herein do not necessarily state or reflect those of the United States Government or the University of California, and shall not be used for advertising or product endorsement purposes.

This report has been reproduced directly from the best available copy.

Available to DOE and DOE contractors from the Office of Scientific and Technical Information P.O. Box 62, Oak Ridge, TN 37831

Prices available from (615) 576.8401, FTS 626.8401

Aveilable to the public from the National Technical Information Service

US. Department of Commerce 5285 Port Royal Rd. Springfield, VA 22161 
Destruction of XM-46 (aka LGP-1846)

Using the Molten Salt Destruction Process

\author{
Ravindra S. Upadhye
}

and

Bruce E. Watkins

Lawrence Livermore National Laboratory

P. O. Box 808

Livermore, CA 94550, USA

\title{
EXECUTTVE SUMMARY
}

The experimental work done on the destruction of the liquid gun propellant XM-46 (or LGP-1846) using the Molten Salt Destruction (MSD) Process at the Lawrence Livermore National Laboratory (LLNL) for the U.S.Army is described in this report.

The current methods of disposal of large quantities of high explosives (HE), propellants and wastes containing energetic materials by open burning or open detonation (OB/OD), or by incineration, are becoming undesirable. LLNL is developing MSD as an alternative to $O B / O D$ and incineration of energetic materials.

A series of 18 continuous experimental runs were made wherein a solution of XM-46 and water was injected into a bed of molten salt comprising the carbonates of sodium, potassium and lithium, along with air. The results from these experiments, described in detail in the main body of this report, show that:

- XM-46 can be safely and completely destroyed in a bed of molten salt at temperatures well below those needed for incineration.

- Under optimum operating conditions, less than $1 \%$ of the chemically bound nitrogen in the XM-46 is converted to NOx, and less than $1 \%$ carbon is converted to $\mathrm{CO}$. 
There exist, however, a number of technical uncertainties:

- We need to understand better why nitrates build up in the salt bath, and what we can do to reduce this amount.

- We need to understand the mechanism of XM-46 oxidation and ways to minimize the formation of $\mathrm{CO}$ and NOx.

In addition, we would like to find out ways by which a more concentrated solution of XM-46 can be introduced into the reactor, so as to increase the throughputs. 


\section{INTRODUCTION}

The current methods of disposal of large quantities of high explosives (HE), propellants and wastes containing energetic materials by open burning or open detonation (OB/OD), or by incineration, are becoming undesirable. OB/OD may result in incomplete combustion and may lead to the formation of secondary toxins. Incineration is facing increased opposition because of the possibility of thermal NOx formation due to high operating temperatures. Also, incineration costs are rising steadily, perhaps due to more stringent controls and permitting delays. Therefore, environmentally acceptable alternatives to incineration and $O B / O D$ will have to be devised to accomplish the task of energetic material waste destruction when effective means of recycling is not feasible.

The Molten Salt Destruction (MSD) Process has been demonstrated for the destruction of $\mathrm{HE}$ and HE-containing wastes(1,2,3). MSD has been used by Anti-Pollution Systems (4), and by Rockwell International (5), to destroy hazardous wastes. MSD converts the organic constituents of the waste into non-hazardous substances such as carbon dioxide, nitrogen and water. Any inorganic constituents of the waste, such as binders and metallic particles, are retained in the molten salt. The destruction of energetic material waste is accomplished by introducing it, together with oxidant gases, into a crucible containing a molten salt, such as sodium carbonate, or a suitable mixture of the carbonates, chlorides or sulfates of sodium, potassium, lithium and calcium. (Fig. 1 shows the flowsheet of the process; the details of the crucible, the experimental set-up and the injection nozzle are given in Figs. 2, 3 and 4 respectively.) The temperature of the molten salt can be varied between $400^{\circ}$ to $900^{\circ} \mathrm{C}$. The organic components of the waste react with oxygen to produce carbon dioxide, nitrogen and steam. The inorganic components, in the form of "ash", are captured in the molten salt bed as a result of wetting and dissolution of the ash. Halogenated hydrocarbons in the waste (which may be present as a result of halogenated solvents in the waste, or as a result of certain halogenated binders for the HE) generate acidic gases such as hydrogen chloride during the pyrolysis and combustion processes occurring in the melt. These are scrubbed by the alkaline carbonates, producing steam and the corresponding salt, such as sodium chloride. The off-gases from the process are sent through standard off-gas 
clean-up processing (such as bag filters or HEPA filters) before being released to the atmosphere. At the end of the process runs, the salt is separated into carbonates, non-carbonate salts, and ash. The carbonates are recycled to the process, and the stable salts are disposed of appropriately.

LLNL has built a small-scale (about $500 \mathrm{~g}$ to $1000 \mathrm{~g}$ throughput per hr) unit to test the destruction of energetic materials using the MSD process as described in detail later in this report. The initial unit operated in a pulsed mode, wherein between $10-20 \mathrm{~g}$ of the feed was injected into the crucible in a few minutes, followed by several minutes of purging with air. This unit was later modified to accept continuous feed. The experiments described in this report were done in the continuous mode. In addition to XM-46, we have destroyed the high explosive HMX (octahydro- 1,3,5,7-tetranitro- 1,3,5,7tetrazocine), RDX (hexahydro-1,3,5-trinitro- 1,3,5-triazine), PETN (2,2-bis[\{nitoxy\}methyl]-1,3-propanediol dinitrate) and TATB ( 2,4,6trinitro-1,3,5-benzenetriamine) in this unit. Our experiments, described in detail later, demonstrate that energetic materials can be safely and effectively treated by MSD.

Technical Basis

The molten salts are typically mixtures of alkali or alkaline earth carbonates and halides. The salts provide excellent heat transfer and reaction media, catalyze oxidation of organics, and neutralize acid gases such as hydrogen chloride by forming stable salts such as sodium chloride $(4,6)$. The relatively high thermal inertia of the melt resists changes in temperature resulting from sudden changes in the feed or heat transfer.

Safety is a major consideration in any process where high explosives or wastes containing high explosives are destroyed. In addition to XM-46, we have successfully and safely destroyed a slurries of 35 weight percent HMX, RDX, PETN and TATB in mineral oil, and 50 weight percent of the above in water. The liquid, in addition to keeping the HE concentration to a safe dilution level, provides a vehicle for handling the HE.

A typical HE, such as $\mathrm{HMX}$, contains sufficient oxygen to propagate a steady back burn without any additional oxygen. To reduce the probability of this, we developed a special nozzle design, shown in Fig. 4. The key features of the nozzle are side injection of 
the feed into the crucible, external cooling of the feed, and introduction of a large volume of gas, such as nitrogen or air, as a carrier for the feed. The side injection, coupled with external cooling, keep the feed temperature well below $200^{\circ} \mathrm{C}$ to minimize spontaneous combustion of the HE. The large volume of inert carrier gas further dilutes the HE, provides a large heat capacity, and keeps the velocity of the feed inside the nozzle relatively high. As a result of all these conditions, the HE decomposes only inside the crucible, and not in the feed nozzle. The high injection velocity also helps maintain a high degree of turbulence and mixing inside the crucible.

Propellants react differently from high explosives when subjected to heat. Therefore, the problem of burn-back may be more severe in some case for propellants than explosives. To avoid the possibility of back-burn, we diluted the propellant with water in the ratio of 2 parts by weight of water per one part by weight of the propellant. This dilution essentially demilitarizes the propellant, and removes it from the category of energetic materials. This diluted mixture can be safely injected into the molten salt bath without any back-propagation.

\section{Experimental Program}

We have built an experimental unit to investigate the applicability of the molten salt destruction process to the destruction of HE and HE-containing wastes. Figure 3 shows a schematic of the current experimental setup.

The crucible (shown in Fig. 2) is made of stainless steel, which is stable in the presence of alkali carbonates. For wastes of high chlorine content, more corrosion resistant materials, such as specialized $\mathrm{Ni}-\mathrm{Cr}$ based alloys or ceramics may be necessary. The crucible has the dimensions 5.76" inside diameter, 6.63" outside diameter, and $24^{\mathrm{N}}$ length. It is fitted with a flange on the top and a removable injection nozzle, described earlier, on the side.

Thermocouples are placed at various locations, including the crucible, the feed nozzle, and the exhaust gas outlet. The coolant gas flow is controlled so as to maintain the feed nozzle temperature under $150^{\circ} \mathrm{C}$. The exhaust line has a demister made from stainless steel wool to trap entrained liquid droplets. Gas sample bottles with manual and solenoid valves are attached to the exhaust line. The whole assembly is placed inside an 
explosion-proof cell, designed to withstand an explosion of up to $500 \mathrm{~g}$ of TNT. Video monitors allow us to observe the experiment without entering the cell during experiments with HEs. All the solenoid valves controlling the sample and the feed sequences are operated remotely. The experimental data are continuously logged on a computer.

To start an experiment, a measured amount of salt is introduced into the crucible from the top, and the top flange is secured. The sample bottles are evacuated, and the vacuum valves are closed off. The sample bottles are now ready to accept samples. A solution of XM-46 and water is made and kept ready to be pumped into the feed tube (see Fig. 3). The nozzle coolant gas is turned on to keep the feed nozzle cool. The heaters are switched on, and data logging is initiated. Once the salt approaches its melting point, the carrier gas in the nozzle is turned on to prevent molten salt from entering the feed nozzle. When the temperature of the melt reaches a desired value (between $500^{\circ} \mathrm{C}$ to $700^{\circ} \mathrm{C}$ in our runs), the system is ready for accepting the energetic waste.

The waste to be treated is injected in to the crucible through the side nozzle described earlier. The oxidant gases, if needed, are introduced through the tube near the center of the crucible (No additional oxygen is necessary for XM-46). The gaseous product of the crucible is sent to the vent as shown in Fig. 3. Gas samples were collected at various intervals after the attainment of a steady state.

A salt sample is withdrawn from the crucible at the end of the final run, and analyzed for traces of the energetic material, such as the constituents of XM-46. The heaters are then shut off, and the unit is allowed to cool. The entrained gas, the coolant gas and the oxidant gas are continued until the salt freezes, at which time the gas flows are shut off.

Results and Discussion

Gas samples were taken during the experiments, and analyzed using a gas chromatograph and mass spectrometer (GC/MS), as well as an on-line IR sensor for $\mathrm{CO}$ for runs 1-6. Table 1 shows the details of the runs made with XM-46 under various operating 
conditions. An explanation of the terms used in the table is given in Appendix 1.

The effect of throughput and temperature on NOx formation is shown in Fig. 5, which shows that:

- The fraction of the chemically bound nitrogen converted to NOx (referred to as the NOx fraction for the remainder of this report) increases with throughput.

- The NOx fraction appears to go through a maximum. It initially increases with temperature $\left(500^{\circ} \mathrm{C}\right.$ to $\left.600^{\circ} \mathrm{C}\right)$, but decreases later on (from $600^{\circ} \mathrm{C}$ to $700^{\circ} \mathrm{C}$ ).

- Even under the worst conditions, namely, high throughput and medium temperature, the NOx fraction is less than $1 \%$.

Figure 6 shows the effect of throughput and temperature on $\mathrm{CO}$ formation. The following observations can be made:

- The fraction of carbon in the feed that is converted to CO (referred to as the $\mathrm{CO}$ fraction for the remainder of this report) decreases with temperature. It is relatively high at low temperature (about $0.9 \%$ at $500^{\circ} \mathrm{C}$ ), decreasing to slightly above $0.1 \%$ at $700^{\circ} \mathrm{C}$, under high throughputs.

- The effect of throughput on the CO fraction is more pronounced at low temperature than at high temperature. For example, the $\mathrm{CO}$ fraction decreases from about $0.9 \%$ to $0.2 \%$ between low and high throughput at $500^{\circ} \mathrm{C}$, whereas a similar change in throughput at $600^{\circ} \mathrm{C}$ shows a change of $0.36 \%$ to $0.17 \%$.

- In all cases, the CO fraction remains less than $1 \%$.

The effect of throughput at low throughputs at $650^{\circ} \mathrm{C}$ on the NOx fraction is shown in Fig. 7, which indicates that the NOx fraction remains under $1 \%$ at all throughputs. 
Table 1: Analysis of $\mathrm{XM}-46$ data

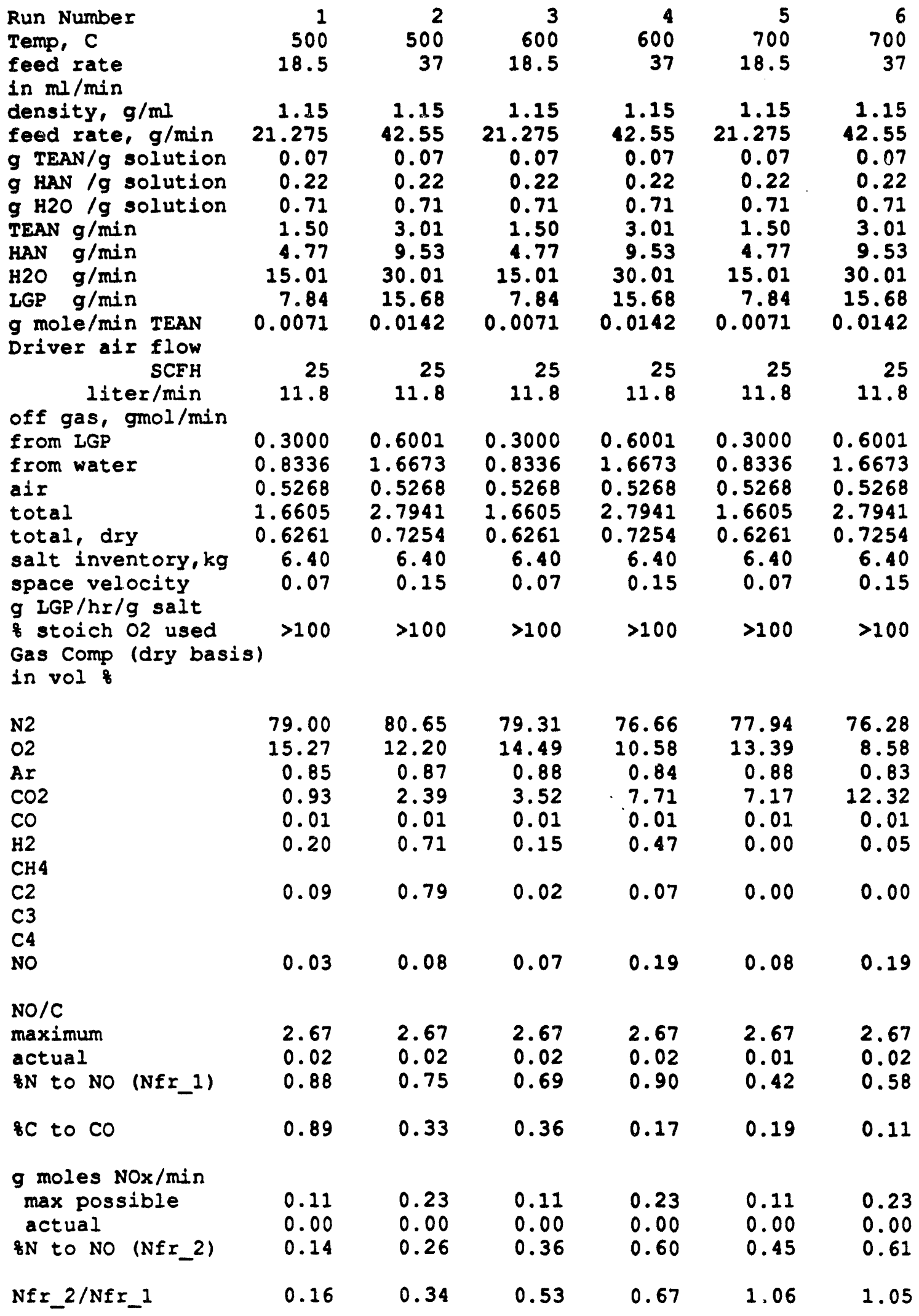


Table 1 (continued): Analysis of XM-46 data

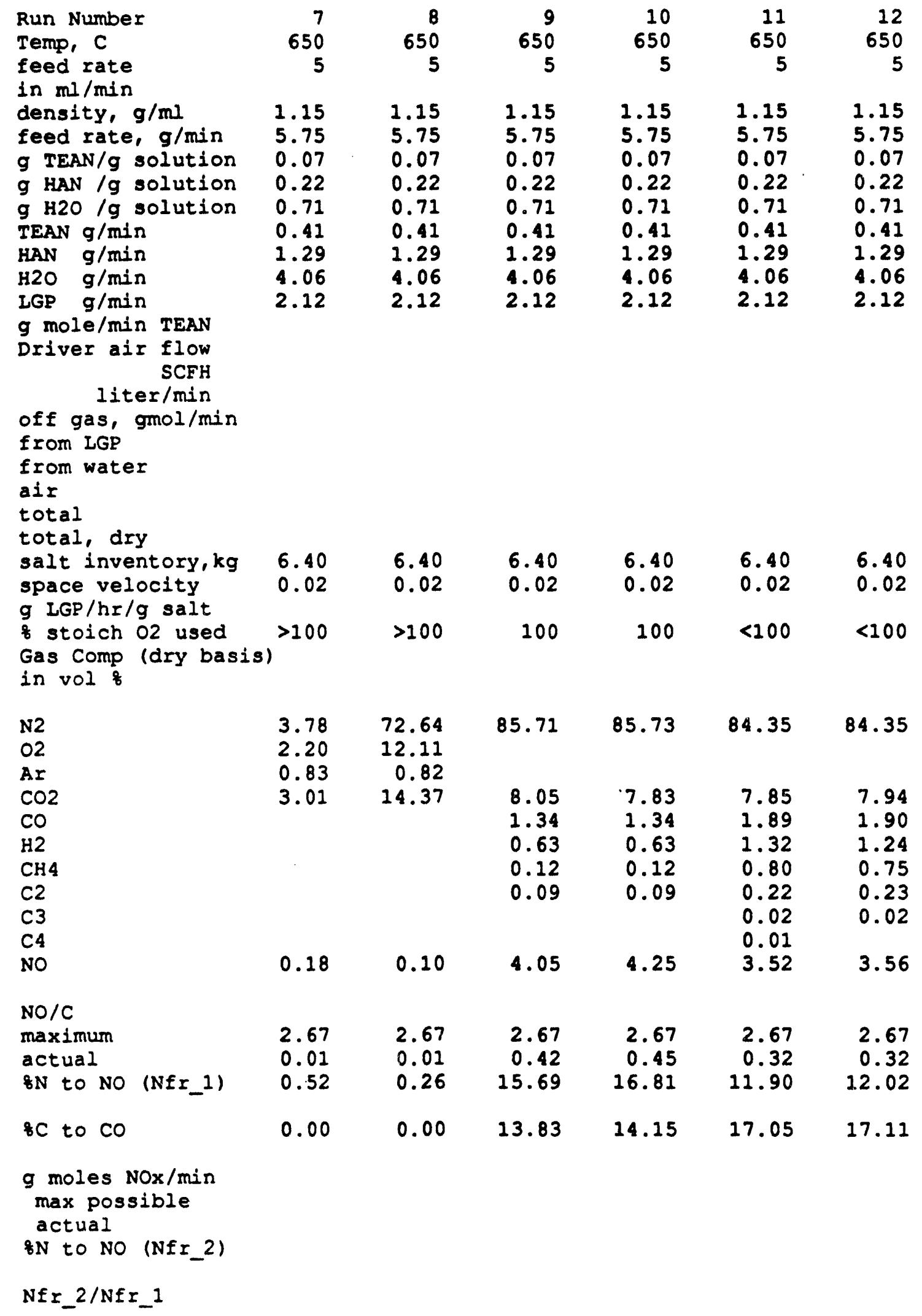


Table 1 (continued): Analysis of XM-46 data

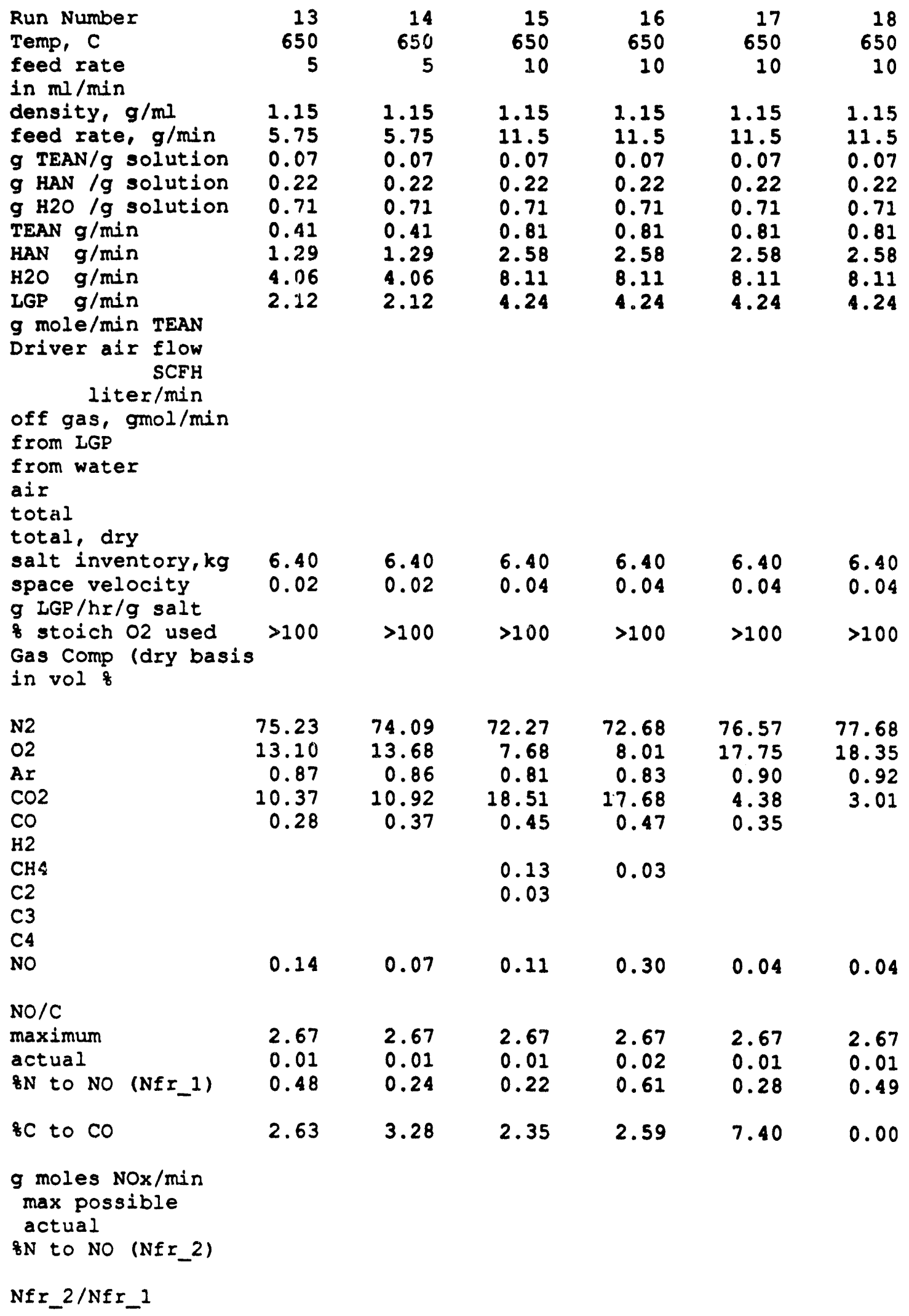


The effect of reducing, neutral and oxidizing conditions under low throughputs at $650^{\circ} \mathrm{C}$ was examined in runs 7 through 18 . Since XM-46 does not need any external oxygen for complete combustion, the addition of the driver air automatically creates oxidizing conditions (runs 7-8, and 13-18). Replacement of the driver air with nitrogen creates neutral conditions (runs 9 and 10). Reducing conditions were obtained by the addition of a small amount of isopropanol to the $\mathrm{XM}-46$, and replacing the driver air with nitrogen (runs 11-12). These data are summarized in Fig. 8, where we have plotted the NOx fraction on the Y-axis, and the fraction of the stoichiometric air used on the $\mathbf{X}$-axis. Note that the numbers used for the $\mathrm{X}$-axis are qualitative, in that $0.5,1.0$ and 1.5 are used to represent reducing, neutral and oxidizing conditions, respectively. Figure 8 shows that the NOx fraction shows a slight increase (12\% to $16 \%$ ) from reducing to neutral conditions, followed by a large drop (16\% to $1 \%$ ) from neutral to oxidizing conditions. (The CO analyses for runs 7 through 18 showed large amount of scatter, and were not considered reliable.)

We examined the composition of the salt bath after $2.5 \mathrm{~L}$ of diluted XM-46 had been processed. The concentration of nitrate in the bed was $4.50 \%$ and of nitrite $0.42 \%$. Thus, roughly $50 \%$ of the nitrate in the XM-46 remained in the salt bath after the termination of the run. It is not known why that much nitrate should remain in the salt bath. Perhaps nitric displaces carbon dioxide from the bed faster than the oxidation of hydrocarbons and hydroxylamine by nitrate. This would be followed by slow decomposition of nitrate to $\mathrm{O}_{2}$, NO and sodium hydroxide. Addition of carbon dioxide to the bed should increase the rate of nitrate decomposition and maintain a low, steady state of nitrate in the salt bath.

We also analyzed the water that condensed in the ice trap during runs 1 to 6 . These results are presented in Table 2. There was a higher concentration of both sodium and potassium in runs with higher feed rates (runs 2, 4, and 6) This is due to greater entrainment of the molten salt by the higher space velocity in the high feed runs.

At $500^{\circ} \mathrm{C}$ the ammonia concentration in the condensate varied between 1200 and $1800 \mathrm{ppm}$, depending on feed rate. As the temperature was increased to $600^{\circ} \mathrm{C}$ the ammonia dropped in half and then to 30 to $70 \mathrm{ppm}$ at $700^{\circ} \mathrm{C}$. It appears that ammonia is 
Table 2

\begin{tabular}{|c|c|c|c|c|c|c|}
\hline $\begin{array}{l}\text { Run } \\
\text { Number }\end{array}$ & 1 & 2 & 3 & 4 & 5 & 6 \\
\hline $\begin{array}{l}\text { Nitrite } \\
\text { Nitrate } \\
\text { Sodium } \\
\text { Potassiu } \\
\mathrm{m}\end{array}$ & $\begin{array}{r}1074 \\
699 \\
252 \\
449\end{array}$ & $\begin{array}{r}1516 \\
1463 \\
873 \\
1855\end{array}$ & $\begin{array}{r}1776 \\
2324 \\
361 \\
702\end{array}$ & $\begin{array}{r}1789 \\
3368 \\
613 \\
1258\end{array}$ & $\begin{array}{c}2425 \text { ND } \\
753 \\
405 \\
900\end{array}$ & $\begin{array}{r}7961 \\
709 \\
1413\end{array}$ \\
\hline $\begin{array}{l}\text { Ammoni } \\
\text { a }\end{array}$ & 1260 & 1820 & 540 & 800 & 32 & 66 \\
\hline pH & 9.34 & 9.79 & 4.54 & 9.13 & 0.91 & 4.36 \\
\hline $\begin{array}{l}\text { Nitrite/ } \\
\text { Nitrate }\end{array}$ & 1.54 & 1.04 & 0.76 & 0.53 & 3.22 & \\
\hline $\mathrm{Na} / \mathrm{K}$ & 0.56 & 0.47 & 0.51 & 0.49 & 0.45 & 0.50 \\
\hline
\end{tabular}

The $\mathrm{pH}$ of the condensate varied greatly from less than 1 to almost 10. The condensate was expected to be slightly acidic due to the presence of dissolved carbon dioxide. This, of course, is moderated by salt entrainment, and subsequent carry over into the condensate vessel.

Conclusions and Future Work

The major conclusions from this work are:

- XM-46 can be safely and completely destroyed in the molten salt bath.

- Under optimum operating conditions, less than $1 \%$ of the chemically bound nitrogen in the XM-46 is converted to NOx, and less than $1 \%$ carbon is converted to $\mathrm{CO}$.

There exist, however, a number of technical uncertainties:

- We need to understand better why so much nitrate builds up in the salt bath, and what we can do to reduce this amount. 
- We need to understand the mechanism of XM-46 oxidation and ways to minimize the formation of $\mathrm{CO}$ and NOx.

In addition, we would like to find out ways by which a more concentrated solution of $\mathrm{XM}-46$ can be introduced into the reactor, so as to increase the throughputs.

Acknowledgments

We wish to acknowledge William Brummond, Ron Kanna, and Tim Gates for their contributions to this project. 
References

1. Upadhye, R.S., et. al., "Destruction of High Explosives and Wastes Containing High Explosives using the Molten Salt Destruction Process", presented at the I\&EC Special Symposium, American Chemical Society, Atlanta, Georgia, September 21-23, 1992.

2. Upadhye, R.S., et. al., Destruction of High Explosives and Wastes Containing High Explosives Using the Molten Salt Destruction Process", paper V-10, presented at the "waste Management of Energetic Materials and Polymers", 23rd International Annual Conference of ICT, Karlsruhe, Germany, June 30 - July 3, 1992.

3. Yossim, S.J., et. al., "Non-polluting Disposal of Explosives and Propellants", U. S. Patent 3,778,320, Decernber 11, 1973.

4. Greenberg, J., "Method of Catalytically Inducing Oxidation of Carbonaceous Materials by the Use of Molten Salts", U.S. Patent 3,647,358, Issued to APS, Inc., 1972.

5. Gay, R.L., et. al., "Destruction of Toxic Wastes Using Molten Salts", presented at the National Meeting of the American Institute of Chemical Engineers, Anaheim, CA, 21 April, 1981.

6. Cooper, J.F., et. al., "Molten Salt Processing of Mixed Wastes with Off-gas Condensation", presented at the 1991 Incineration Conference, Knoxville, TN, 13 May 1991. Also, UCRL-JC-107288, Lawrence Livermore National Laboratory, Livermore, CA, 1991.

7. Henry, R.E., et. al., "Large Scale Vapor Explosions", Proceedings of the Fast Reactor Safety Meeting, April 2-4, 1974, Beverly Hills, CA (NTIS Ref. No. CONF-740401-P?).

8. Gay, R.L., et. al., "Treatment of Propellant and Explosive Wastes using Molten Salt Oxidation", presented at the I\&EC Special Symposium, American Chemical Society, Atlanta, Georgia, September 21-23, 1992. 
Appendix 1

Explanation of the terms used in Table 1

Run Number: ID number for the run

Temp, C: Salt temperature, in degrees Celsius

Feed rate: measured feed rate, $\mathrm{ml} / \mathrm{min}$

Density: calculated density of the feed solution

Feed rate, g/min: product of volumetric feed rate and density

The next three rows represent calculated values of the concentrations of TEAN, HAN and water in units of $g$ per gram of solution. These values are in turn used to calculate the absolute flow rates of these three components in units of $\mathrm{g} / \mathrm{min}$. The next row represents the flow rate of LGP into the molten salt unit, in units of $\mathrm{g} / \mathrm{min}$.

Salt inventory: Weight of salt in the crucible, $k g$

Space velocity: Flow rate of LGP in units of $\mathrm{g} / \mathrm{hr}$ divided by grams of salt in the vessel

The next row indicates whether the experiments were conducted in (nominal) reducing, neutral or oxidizing conditions. Most experiments are under oxidizing conditions because the driver gas used in the nozzle was air. Runs 9 and 10 are under neutral conditions because the driver gas used was nitrogen. To obtain reducing conditions, such as in runs 11 and 12, small amounts of isopropanol were added to the feed, and nitrogen was used as the driver gas.

The next 10 rows contain the results of gas analyses on the off-gas. They are expressed in volume (or mole) percents. C2, C3 and $\mathrm{C} 4$ represent all hydrocarbon compounds with carbon chain lengths of 2,3 and 4 respectively.

The next two rows represent maximum possible and actual ratios of $\mathrm{NO}$ in the off-gas to the total carbon in the off-gas. If ALL the $\mathrm{N}$ in the LGP is converted to NO, this ratio will be 2.67. Thus, the ratio of actual to maximum represents the fraction of the chemically bound nitrogen in the LGP that is converted to NO. This ratio is referred to as Nfr_1. 
The next row shows the percentage of the carbon in the LGP that is converted to $\mathrm{CO}$.

For run numbers 1 through 6 , for which reliable air flow data are available, we performed the NOx fraction calculations based on the total product gas flow and the composition of the NO in the product gas. Once again, we calculated the NO fraction, referred to as Nfr_2. Finally, the ratio of $\mathrm{Nfr}_{2} 2$ to $\mathrm{Nfr}_{-} 1$ provides a comparison of the two methods of calculating the NO fraction. 


\section{We are developing a molten salt process for wastes containing energetic materials}

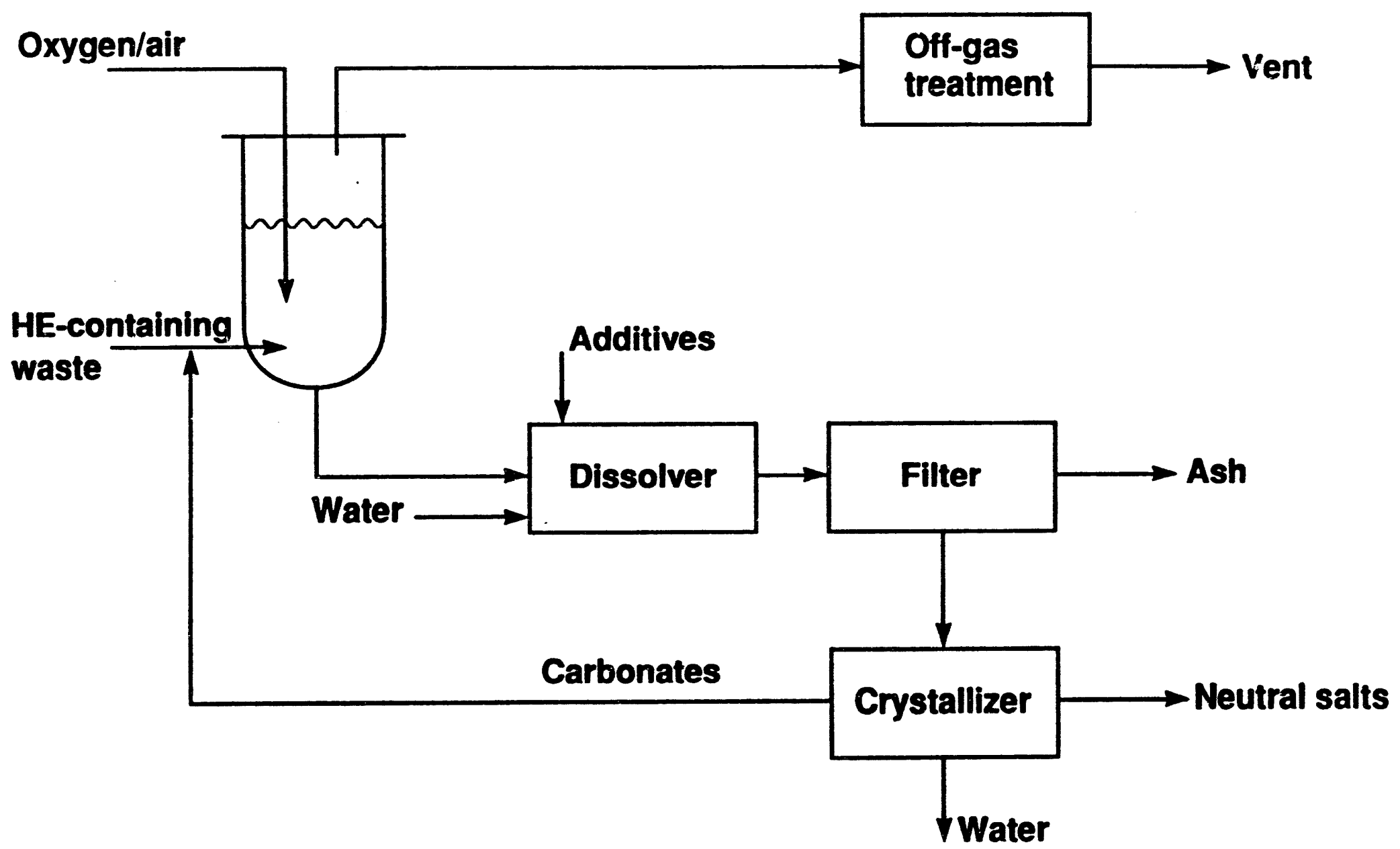




\section{Details of the crucible}

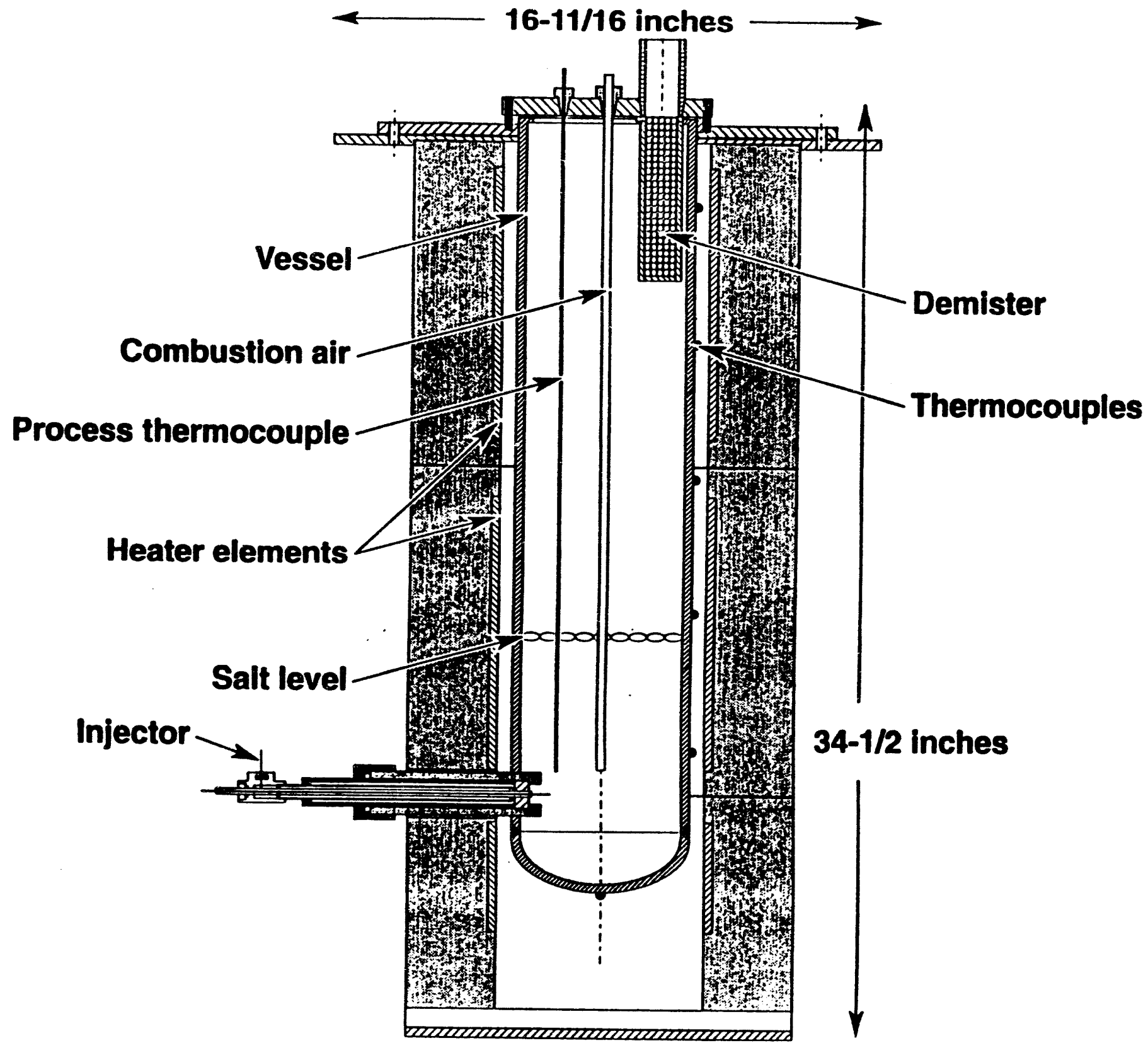




\section{Molten salt destruction of energetic materials}

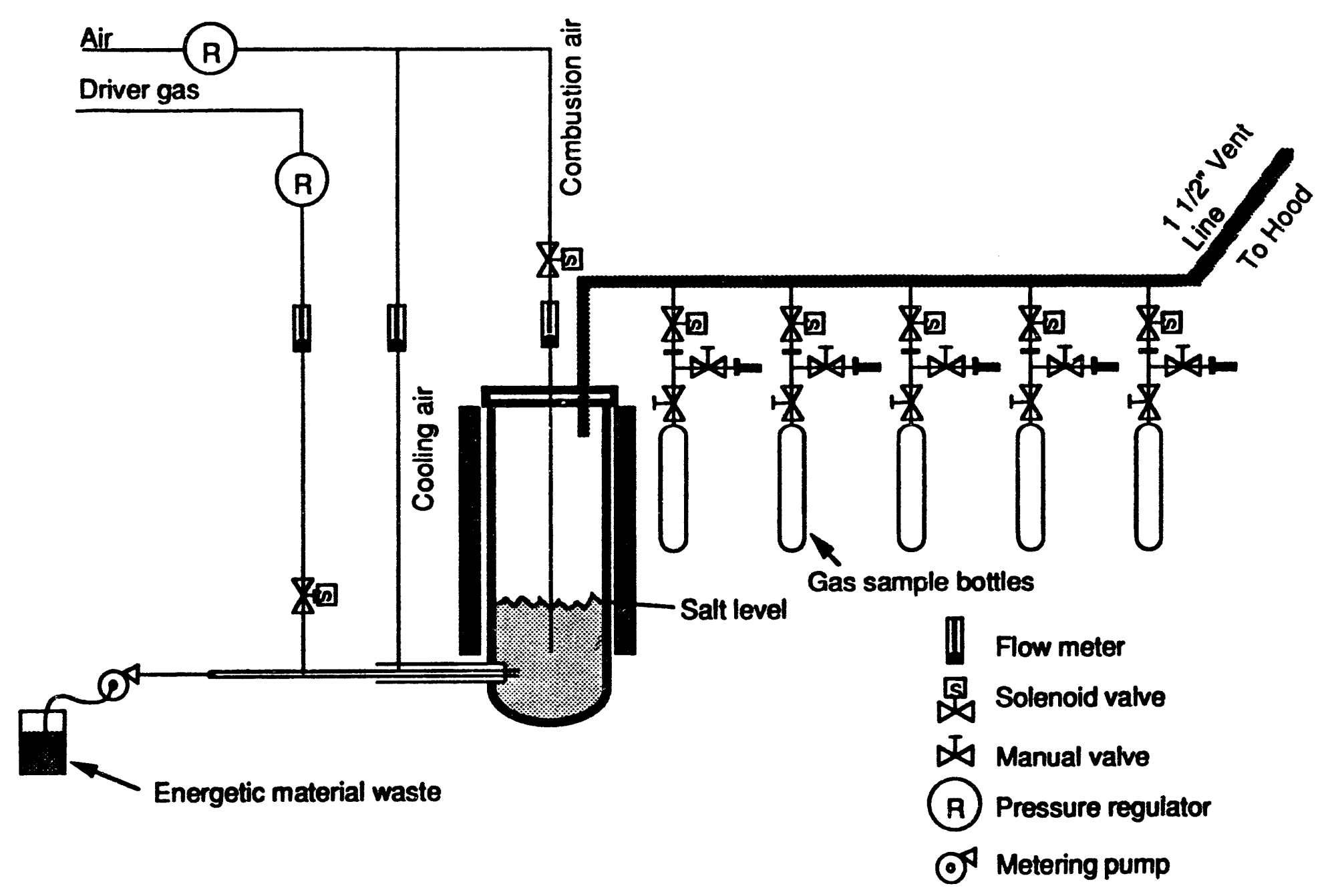

Figure 3 


\section{Details of the injector nozzle}

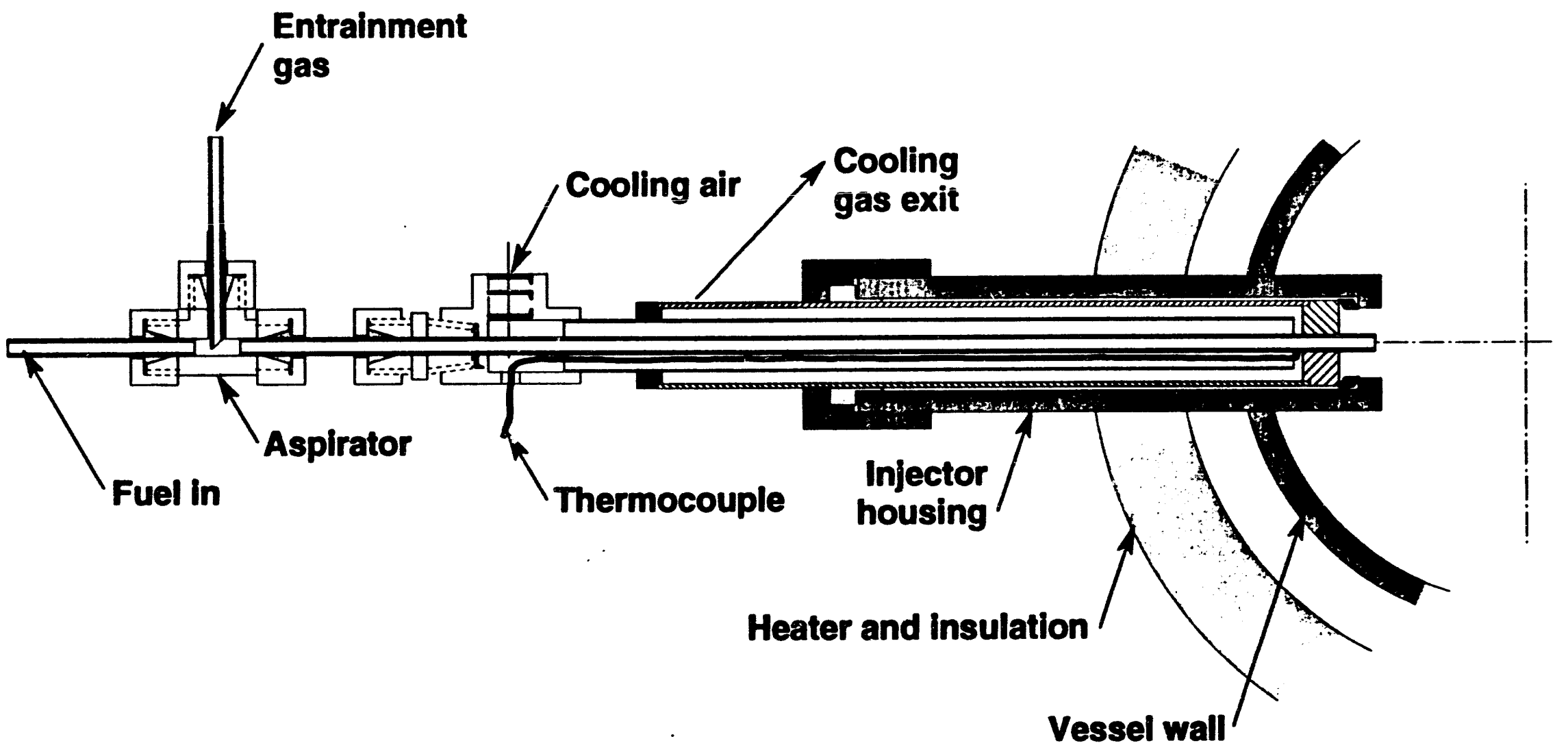




\section{Effect of throughput and temperature on NOx formation}

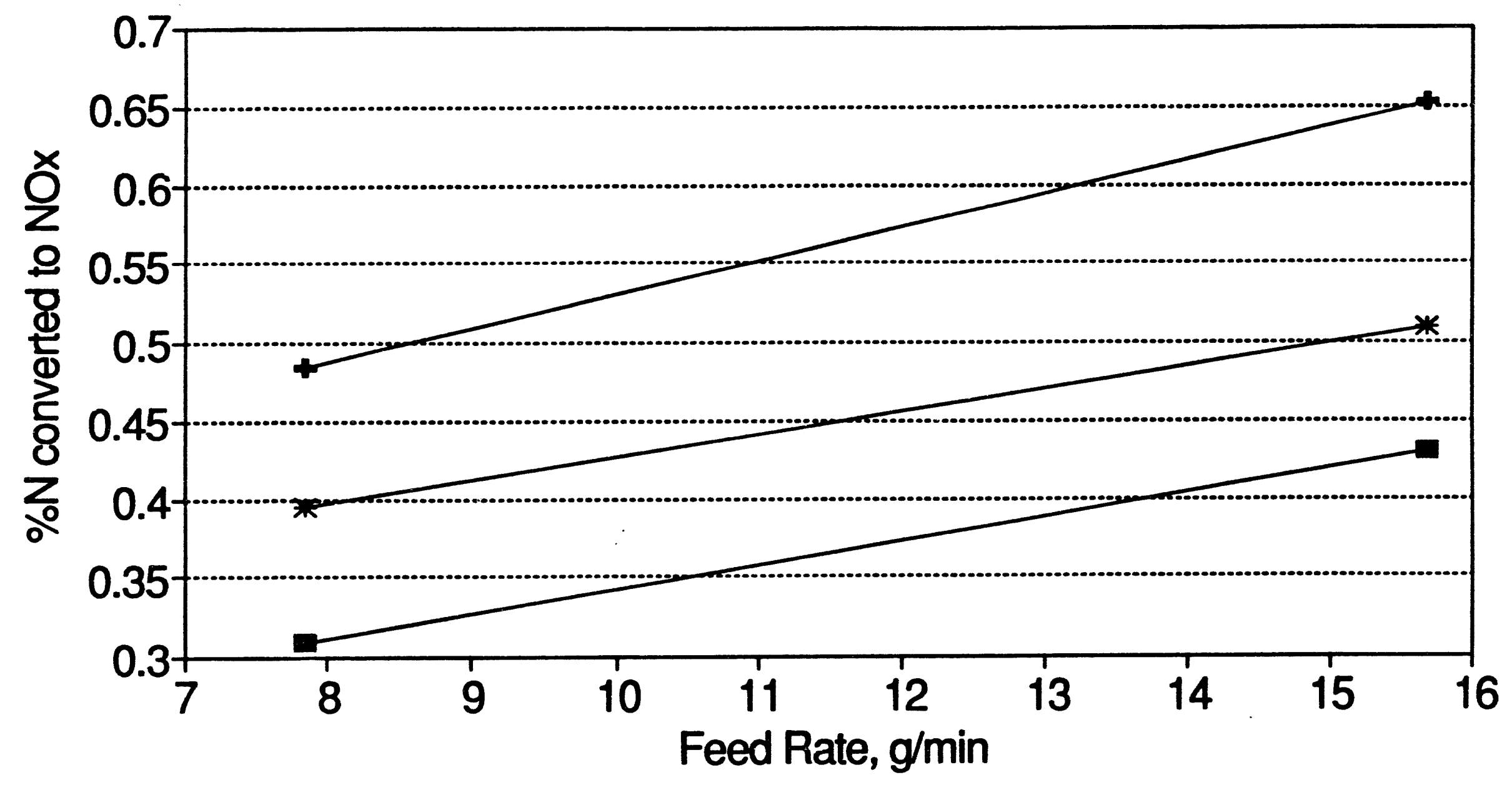

$$
\rightarrow 500 C-600 C \rightarrow 700 C
$$




\section{Effect of throughput and temperature on $\mathrm{CO}$ formation}

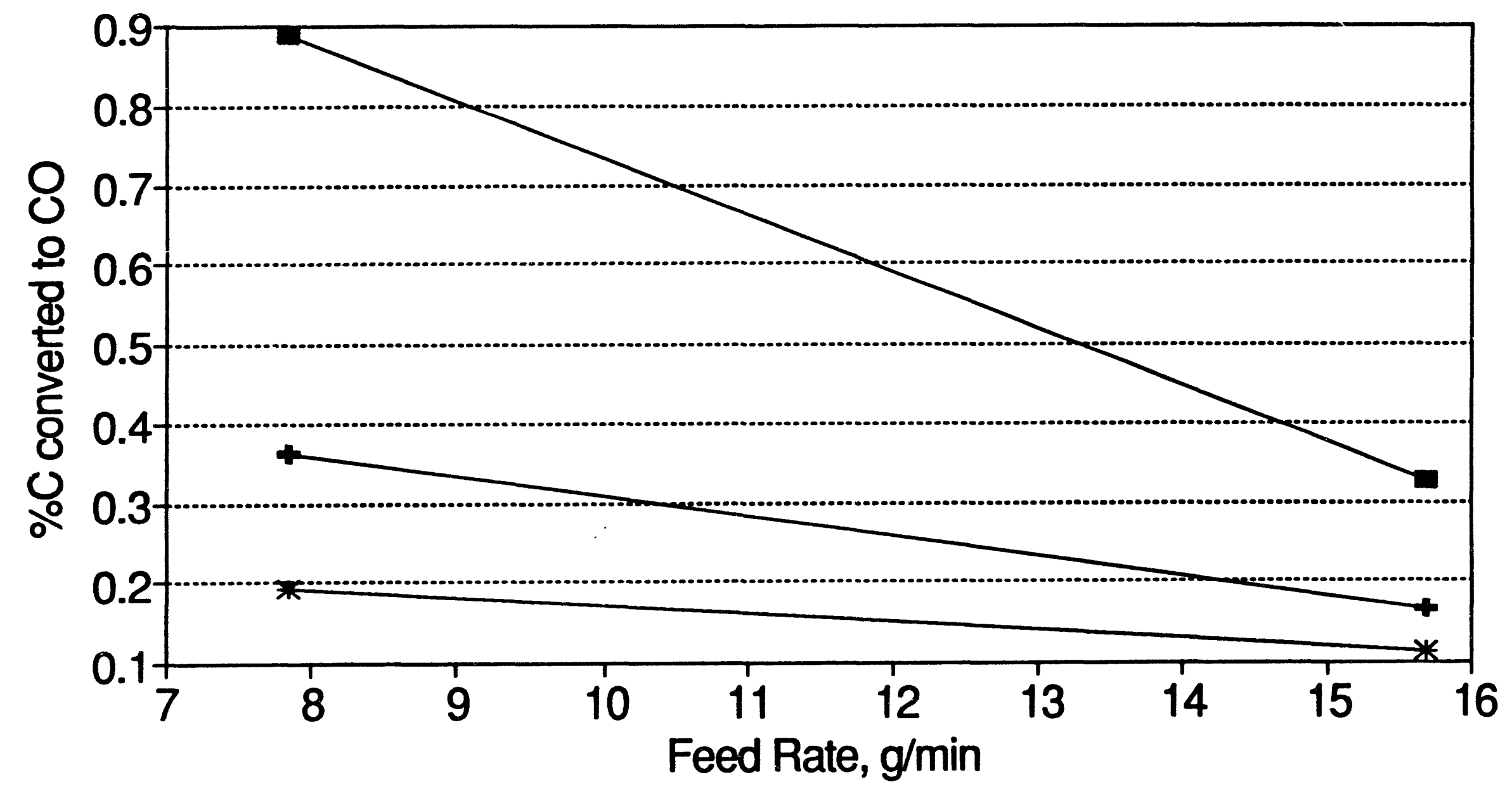

$\rightarrow 500 C+600 C \rightarrow 700 C$ 


\section{Effect of throughput on NOx at $650 \mathrm{C}$}

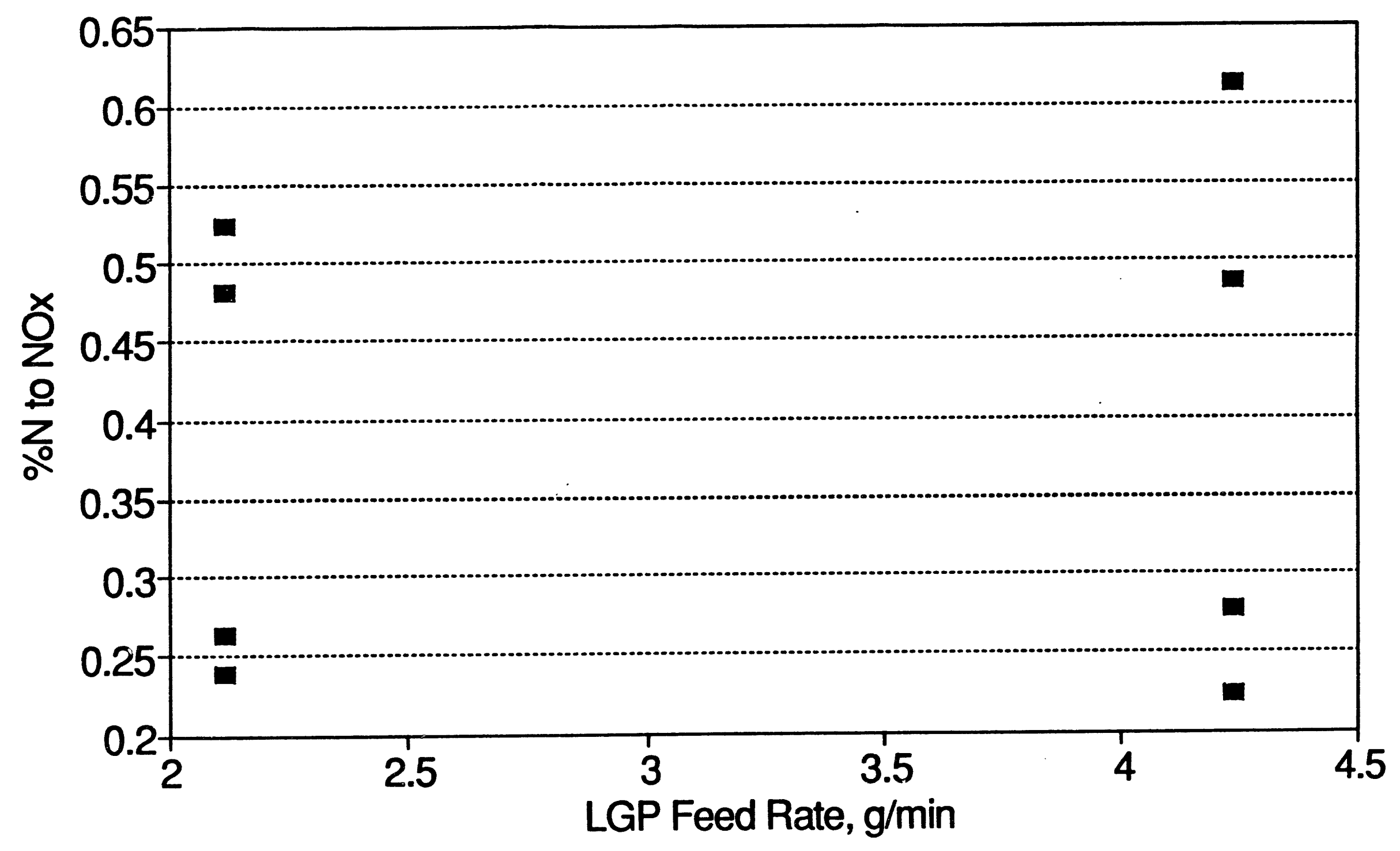

Figure 7 


\section{Effect of Oxygen on NOx at $650 \mathrm{C}$}

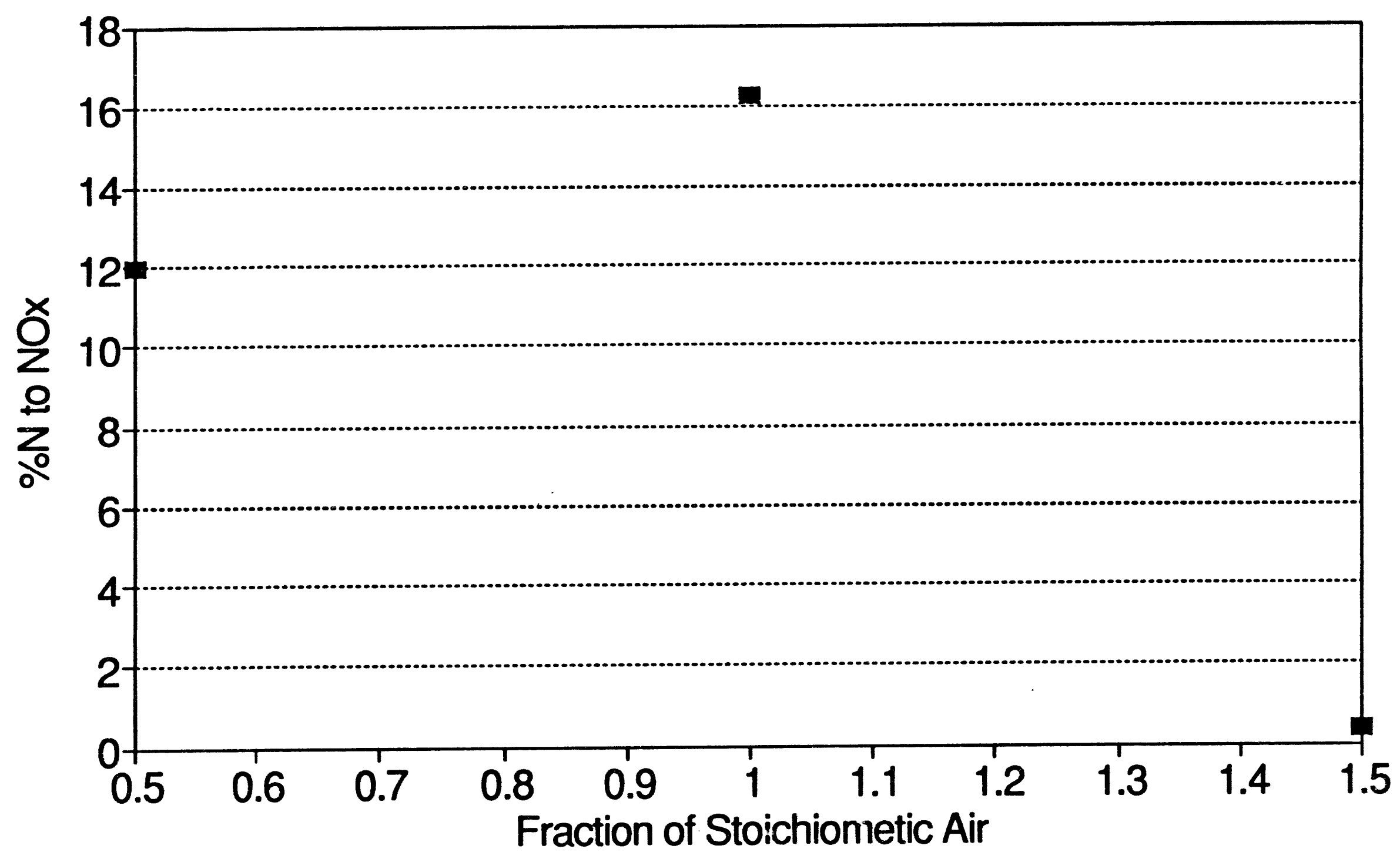

Figure 8 
$r$
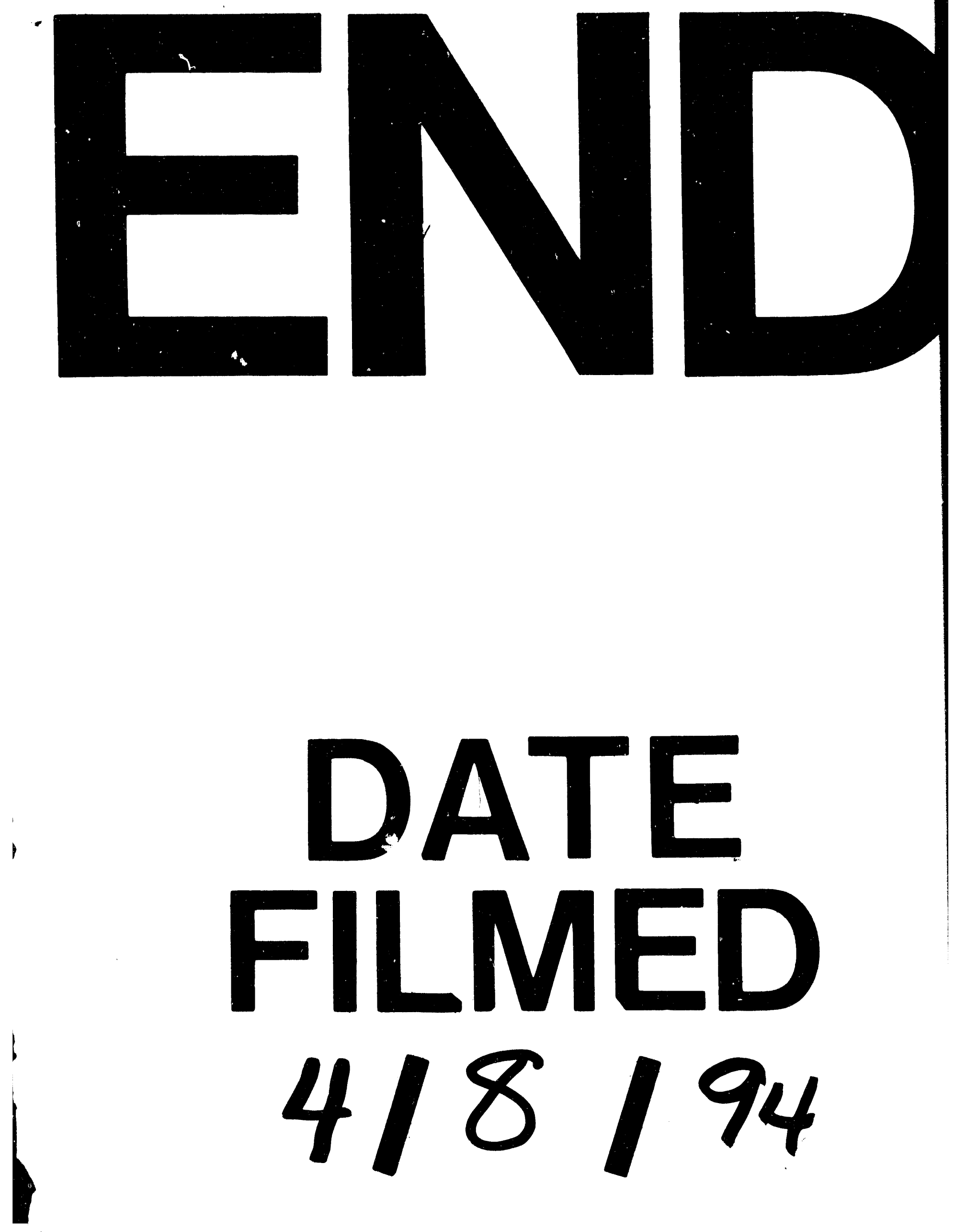
